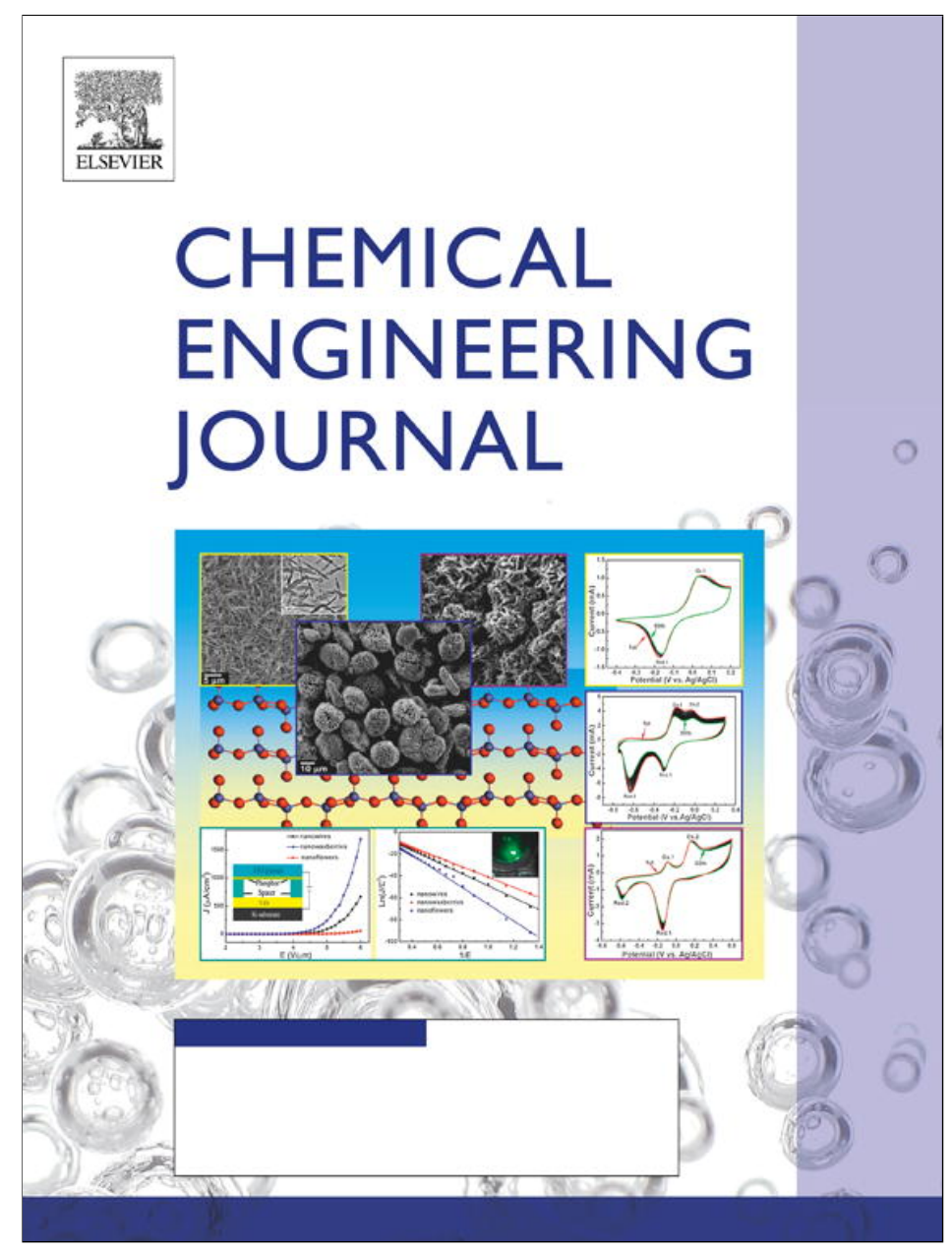

(This is a sample cover image for this issue. The actual cover is not yet available at this time.)

This article appeared in a journal published by Elsevier. The attached copy is furnished to the author for internal non-commercial research and education use, including for instruction at the authors institution and sharing with colleagues.

Other uses, including reproduction and distribution, or selling or licensing copies, or posting to personal, institutional or third party websites are prohibited.

In most cases authors are permitted to post their version of the article (e.g. in Word or Tex form) to their personal website or institutional repository. Authors requiring further information regarding Elsevier's archiving and manuscript policies are encouraged to visit: 


\title{
Mechanism of $\mathrm{Pb}^{2+}$ removal from aqueous solution using a nonliving moss biomass
}

\author{
Bamidele I. Olu-Owolabi ${ }^{\text {a }}$, Paul N. Diagboya ${ }^{\mathrm{a}, *}$, William C. Ebaddan $^{\mathrm{b}}$ \\ ${ }^{a}$ Department of Chemistry, Faculty of Science, University of Ibadan, Ibadan, Nigeria \\ ${ }^{\mathrm{b}}$ Department of Agronomy, Faculty of Agriculture, University of Ibadan, Ibadan, Nigeria
}

\section{H I G H L I G H T S}

- The moss plant Barbula lambarenensis (RBL) will be useful for metal adsorption from aqueous solution.

- The maximum adsorption capacity $\left(Q_{0}\right)$ for $\mathrm{Pb}$ adsorption is $62.50 \mathrm{mg} / \mathrm{g}$ at $298 \mathrm{~K}$ and $90.91 \mathrm{mg} / \mathrm{g}$ at $323 \mathrm{~K}$.

- The $\mathrm{pH}$ for optimum adsorption is 5.0 while maximum adsorption was attained in $30 \mathrm{~min}$.

- The adsorption data obeyed the pseudo-second-order model.

- The free energy changes $\left(\Delta G^{\circ}\right)$ are positive and the reaction is exothermic.

\section{A R T I C L E I N F O}

\section{Article history:}

Received 18 March 2012

Received in revised form 1 May 2012

Accepted 1 May 2012

Available online 11 May 2012

\section{Keywords:}

Lead

Biosorption

Barbula lambarenensis

Kinetics

Thermodynamics

\begin{abstract}
A B S T R A C T
Biosorption of lead (II) ions onto raw biomass of the moss plant Barbula lambarenensis has been studied using the batch equilibrium adsorption method. Equilibrium isotherms, kinetics and thermodynamic parameters have been evaluated. The FT-IR analysis showed that likely functional groups responsible for the adsorption are carboxyl, carbonyl, amides and hydroxyl groups. The $\mathrm{pH}$ for optimum adsorption is 5.0. Equilibrium data fit well to the Langmuir isotherm. The estimated maximum adsorption capacity was found to be $62.50 \mathrm{mg} / \mathrm{g}$ at $298 \mathrm{~K}$ and $90.91 \mathrm{mg} / \mathrm{g}$ at $323 \mathrm{~K}$. The kinetic data obeyed the pseudo-second-order model. The free energy changes $\left(\Delta G^{\circ}\right)$ are positive and the reaction is exothermic with decreased randomness at the sorbent/solution interface. Taking into account its good adsorption capacity, ease of sample treatment, as well as availability, the biomass of $B$. lambarenensis is a promising cost-effective biosorbent for $\mathrm{Pb}^{2+}$ removal from aqueous environment.
\end{abstract}

(C) 2012 Elsevier B.V. All rights reserved.

\section{Introduction}

Several techniques have been employed for metal ions removal from water: filtration, chemical precipitation, ion exchange, reverse osmosis, electrochemical treatment, membrane technology, evaporation recovery, solvent extraction, adsorption on activated carbon, etc. [1]. But these techniques are limited by techno-economic considerations as well as environmental friendliness. The ability of biomaterials to remove heavy metals through biosorption has proved to be highly efficient, easy to handle, environment-friendly, and economically feasible. This has attracted plenty of attentions in recent years [2-4] because biomaterials are: (i) available in abundance and cheap, (ii) easy to obtain and process, and (iii) available as waste type or nuisance [5].

* Corresponding author. Present address: National Center for Nanoscience and Nanotechnology, Beijing 100190, China. Tel.: +86 18310212731, +234 8038052553.

E-mail address: pauldn2@yahoo.com (P.N. Diagboya).
Several workers have investigated and reported various plant materials' ability to adsorb different metals from solution. These include mungbean husk [5], hazelnut shell [6], almond shell [6], pine [7], lignin [8], tea leaves [9], tree ferm [10], groundnut husks [11], sphagnum moss peat [12], sawdust [13], rice hulls [14], chitosan [14], sugarcane bagasse [15], cocoa shell [16], and rice husk [17]. However, some major limitations of these biosorptions are that some of them have not yielded satisfactory results (high metal adsorption capacity) and others that yielded good results may not locally be available.

Biosorption involves one or more of several processes including metal ion coordination complex, ion exchange, and covalent linkage to biomass components. However, biomass of different origins have different sorption capacities because of their different affinities for different metals; and since there is no way to predict metal sorption capacity of a certain biomass, the search for an ideal techno-economically feasible biosorbent, that meets the above listed criteria is continuing [5].

There has been no reported work on $\mathrm{Pb}^{2+}$ removal from aqueous solution using the moss Barbula Lambarenensis (BL). Ogunfowokan 
et al. [18] have shown the living biomass of BL is a bio-indicator of heavy metals in the environment. This may be an indication of the ability of the dead biomass to adsorb these metals. Since BL is abundantly available at no cost, and $\mathrm{Pb}^{2+}$ pollution of surface waters is a major international challenge, the BL was investigated for the development of a BL-based procedure for the removal of $\mathrm{Pb}^{2+}$ from aqueous solution.

In this study, the sorption behavior of $\mathrm{Pb}^{2+}$ from aqueous solution using BL was studied under various conditions; contact time, solution $\mathrm{pH}$, temperature and sorbent dose, and sorbate concentration, with the aim of determining the mechanism for the removal of $\mathrm{Pb}^{2+}$ from aqueous solution by biomass of $B$. Lambarenensis.

\section{Methodology}

\subsection{Sampling, pre-treatment and characterization of biosorbent material}

The B. Lambarenensis was obtained in August 2011 in Agbor $\left(6^{\circ} 11^{\prime} 6^{\prime \prime} \mathrm{E} ; 6^{\circ} 15^{\prime} 9^{\prime \prime} \mathrm{N}\right)$, Delta State, Nigeria; washed severally with tap water and deionized water to remove impurities, then air-dried, ground, sieved through a $0.5 \mathrm{~mm}$ mesh size sieve, and the sieved particles were used for the study. This was called the raw BL (RBL).

The Specific Surface Area (SSA) of the sample was determined using the methods of Sears [19] and Iler [20]. The bulk density and specific gravity of the RBL sample was determined as described by Radojevic and Bashkin [21]. The $\mathrm{pH}$ at the point zero charge ( $\mathrm{pH}$ PZC) was determined as described by Unuabonah et al. [22]. The determination of RBL surface properties is necessary because the particle sizes are most likely heterogeneous and these properties aid in estimating the degree of metal sorption. The SSA of RBL has been determined as $11.352 \mathrm{~m}^{2} / \mathrm{g}$, while the bulk density and specific gravity are $0.424 \mathrm{~g} / \mathrm{cm}^{3}$ and $0.172 \mathrm{~g} / \mathrm{cm}^{3}$, respectively. The $\mathrm{pH}$ PZC value is 7.01. This is important because it marks the $\mathrm{pH}$ where the surface functional groups do not contribute to the $\mathrm{pH}$ of the solution, and in an applied electric field, the electrophoretic mobility of the particles would be zero [23].

The Fourier Transform Infrared (FTIR) spectra of the RBL biosorbent were obtained using Perkin Elmer Spectrum 1 FTIR spectrophotometer. About $0.1 \mathrm{~g}$ of the processed dry RBL biosorbent in powder form along with $\mathrm{KBr}$ were ground into fine particles and pressed to make pellets with was used to obtain the FT-IR spectrum in the scanning frequency from 4500 to $500 \mathrm{~cm}^{-1}$.

\subsection{Biosorption procedures}

$1000 \mathrm{mg} / \mathrm{L}$ of standardized $\mathrm{Pb}^{2+}$ stock solution was prepared from the analytical grade chloride salt. Working solutions of required concentrations were prepared from this stock as required. Replicate batch experiments were used to determine metal sorption capacity of the biomass in $60 \mathrm{~mL}$ polyethylene bottles by contacting approximately $0.1 \mathrm{~g}$ of the RBL biomass with $20 \mathrm{~mL}$ of metal solution, except where otherwise stated, for determining effect of $\mathrm{pH}$, time, temperature and sorbate concentration. The sorbent-sorbate mixtures were shaken on a mechanical shaker during the course of the adsorption experiment and concentrations of metal in the filtrate solutions were determined using the Buck Scientific 205 Atomic Absorption Spectrometer (AAS) with air-acetylene flame on absorbance mode.

The quantity of metal adsorbed by RBL after each specified incubation period was calculated using the following equation:

$Q=\frac{\left(C_{o}-C_{e}\right) V}{M}$

where $Q, C_{o}$ and $C_{e}$ are the cation adsorbed $(\mathrm{mg} / \mathrm{g})$, the initial and equilibrium metal concentrations in the solution $(\mathrm{mg} / \mathrm{L})$, respectively; and $V(\mathrm{~mL})$ and $M(\mathrm{~g})$ are respectively the volume of solution and mass of adsorbent.

To obtain insights into the surface properties and degree of affinity of RBL, sorption data were tested against the Langmuir, Freundlich and Dubinin-Radushkevich equilibrium isotherms using the linear forms of these models in Eqs. (2.2) and (2.3).

Langmuir : $\frac{C_{e}}{q_{e}}=\frac{1}{Q_{o} b}+\frac{C_{e}}{Q_{o}} \quad$ (Linear form)

Freundlich : $\log q_{e}=\log K_{f}+\frac{1}{n} \log C_{e} \quad$ (Linear form)

where $Q_{o}(\mathrm{mg} / \mathrm{g})$ and $q_{e}$ is the maximum adsorption and amount of solute adsorbed per unit weight of adsorbent $(\mathrm{mg} / \mathrm{g})$, respectively. $C_{e}$, is same as above; $b, K$, and $n$ are isotherm constants obtained from the slopes and intercepts.

The Dubinin-Radushkevich isotherm which describes adsorption on both homogenous and heterogeneous surfaces [24] is shown in the following equation:

$\operatorname{Inq} q_{e}=\operatorname{InX} X_{m}-\beta \varepsilon^{2}$

where $X_{m}$ and $\beta$ are the Dubinin-Radushkevich monolayer adsorption capacity $(\mathrm{mg} / \mathrm{g})$ and the constant related to sorption energy respectively, and $\varepsilon$ is the Polanyi potential which is related to the equilibrium concentration (Eq. (2.5)).

$\varepsilon=R \operatorname{TIn} \frac{1}{C_{e}}$

In describing the kinetics of the biosorption, the pseudo-first-order, pseudo-second-order, Elovich, and Intra-particle diffusion models have been applied to the biosorption data. The Lagergren pseudofirst-order and pseudo second-order rate equations [25] were tested using their simplified equations in (2.6) and (2.7) respectively:

$\log \left(q_{e}-q_{t}\right)=\log q_{e}-\frac{k_{1}}{2.303} t$

where $q_{e}$ and $q_{t}$ are the amounts of metals sorbed ( $\mathrm{mg} / \mathrm{g}$ ) at equilibrium and at time $t$, respectively; and $k_{1}$ is the rate constant of pseudo-first-order sorption $\left(\mathrm{min}^{-1}\right)$. The $q_{e}$ and rate constants $k_{1}$ were calculated from the slope and intercept of the plot of $\log \left(q_{e}-q_{t}\right)$ vs. $t$.

$\frac{t}{q_{t}}=\frac{1}{k_{2} q_{e}^{2}}+\frac{t}{q_{e}}$

where $k_{2}$ is the rate constant of pseudo-second-order sorption. The pseudo-second-order rate constants $k_{2}$ and $q_{e}$ values were calculated from the slope and intercept of the plots $t / q$ vs. $t$.

The Elovich model equation [26] in Eq. (2.8) was used.

$q_{t}=\frac{1}{\beta} \operatorname{In}(\alpha \beta)+\frac{1}{\beta} \operatorname{In}(t)$

where $\alpha$ is the initial adsorption rate $(\mathrm{mg} / \mathrm{g} / \mathrm{min})$ and $\beta$ is the desorption constant $(\mathrm{g} / \mathrm{mg})$ during any one experiment.

The linearized form of the intra-particle diffusion model equation [26] was used as shown in Eq. (2.9).

$\log R=K_{i d}+\alpha \log (t)$

where $R$ is percentage metal ion adsorbed, $t$ is contact time, $\alpha$ is gradient of linear plots and depicts the adsorption mechanism, $K_{i d}$ is intra-particle diffusion rate constant $\left(\mathrm{h}^{-1}\right)$

The biosorption thermodynamic parameters; enthalpy $\left(\Delta H^{o}\right)$, entropy $\left(\Delta S^{o}\right)$, Gibbs free energy $\left(\Delta G^{o}\right)$ and equilibrium constant $(K c)$, were determined for the experimental systems using Eqs. (2.10)-(2.12), plotting graph of In $K_{c}$ verses $1 / T$ and using the slope and intercept to evaluate the values of $\Delta H^{o}$ and $\Delta S^{o}$. 
$K_{c}=\frac{q_{e}}{C_{e}}$

$\Delta G^{0}=-R \operatorname{TIn} K_{c}$

$\operatorname{InKc}=-\frac{\Delta H^{o}}{R T}+\frac{\Delta S^{o}}{R}$

\section{Results and discussion}

\subsection{Fourier Transform Infrared (FT-IR) spectroscopy}

FT-IR test spectra of unloaded RBL biomass showed several absorption peaks between the scanning frequency range of $4500-500 \mathrm{~cm}^{-1}$ (Fig. 1). The broad band positioned around $3400 \mathrm{~cm}^{-1}$ is indicative of the stretching band of the carbonyl double bond from some carboxylic acids and their salts, a stretching vibration of free hydroxyl functional groups of aromatic and aliphatic origins, and possibly $\mathrm{N}-\mathrm{H}$ stretch of amides. The water content in the RBL biomass and the numerous free hydroxyl groups in the polysaccharide structure of this moss plant wall may explain the presence of the band. The sharp absorption just below $3000 \mathrm{~cm}^{-1}$ is indicative of $\mathrm{C}-\mathrm{H}$ stretch likely from alkanes while the band at around $2350 \mathrm{~cm}^{-1}$ is suggestive of cumulative double bonds stretch of $\mathrm{O}=\mathrm{C}=\mathrm{O}$. The band around 1700 is characteristic of the $\mathrm{C}=\mathrm{O}$ stretch of carbonyl double bond either from free or esterified carboxyl groups. However, closer band frequencies at $1655 \mathrm{~cm}^{-1}$ have been attributed to amide-I of protein secondary structures. The absorption peak at about $1424 \mathrm{~cm}^{-1}$ suggests aromatic methyl group/methyl ketone and carboxylate vibrations or likely $\mathrm{C}-\mathrm{H}$ deformations of alkanes. The strong band around $1090 \mathrm{~cm}^{-1}$ is due likely to the $\mathrm{C}-\mathrm{OH}$ bond and $-\mathrm{C}-\mathrm{C}-$ stretchings, which are characteristic for polysaccharides. Peaks below $1000 \mathrm{~cm}^{-1}$ have been attributed to such groups as aromatic $\mathrm{C}-\mathrm{H}$ bending vibrations $\left(874 \mathrm{~cm}^{-1}\right)$, thioesters $\left(672 \mathrm{~cm}^{-1}\right)$, but majorly plane deformations. Similar observations have been reported by Yan et al. [4], Pehlivan et al. [6], Chakravarty et al. [27] and Yao et al. [28].

The pristine RBL spectra and that of the $\mathrm{Pb}^{2+}$-loaded were compared. Although the spectra were similar, the peaks frequency and intensity of most functional groups in the Pb-loaded RBL were shifted slightly than those in the pristine; for instance, some characteristic peak locations of RBL shifted from 3421, 1638, 1513, $1426,1078,1035,795$, and $692 \mathrm{~cm}^{-1}$ to $3413,1639,1516,1428$,

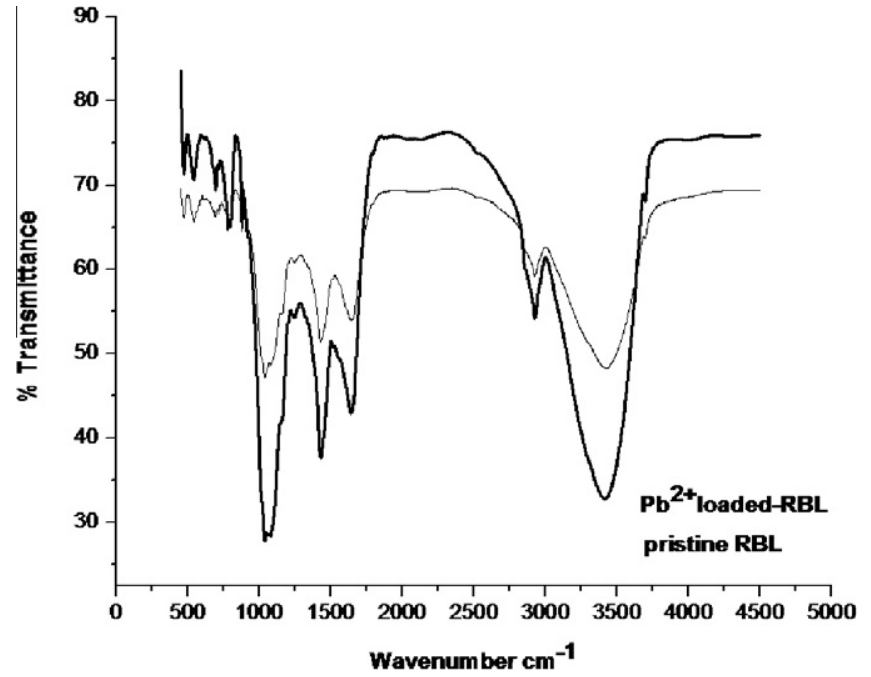

Fig. 1. FTIR spectra of raw Barbula Lambarenensis (RBL).
1076, 1036, 769, and $694 \mathrm{~cm}^{-1}$, respectively, after $\mathrm{Pb}^{2+}$ ions adsorption (peak values not shown in Fig. 1). These shifts may be attributed to the counter ions changes associated with the respective functional groups anions when they act as proton donors, suggesting their participation in $\mathrm{Pb}^{2+}$ ion adsorption [4,6,27]. No marked change in frequency was observed between both spectra in the region just below $3000 \mathrm{~cm}^{-1}$ (hydroxyl functional groups). However, the broadening of the peak in the pristine decreases indicating that the hydrogen bonding of the hydroxyl groups decreases after $\mathrm{Pb}$ adsorption. These observations suggest the involvement of carboxyl, carbonyl, thioesters, amides and hydroxyl functional groups in $\mathrm{Pb}^{2+}$ ions biosorption.

\subsection{Effect of $\mathrm{pH}$ on adsorption}

Establishing the capacity of RBL as new biosorbent material for $\mathrm{Pb}^{2+}$ requires knowing the optimum $\mathrm{pH}$ for adsorption. This was determined by equilibrating the sorbent-sorbate mixture containing $500 \mathrm{mg} / \mathrm{L}$ of $\mathrm{Pb}^{2+}$ at $\mathrm{pH}$ values between 3 and 7. $\mathrm{pH}$ is an important biosorption parameter because it affects the activities of functional groups present on the surface of the biosorbent which are responsible for adsorption, and affects competitive adsorption of ions to sorption sites $[7,24,26]$. Thus, various biosorbents have various optimum sorption $\mathrm{pH}$ for different metals.

As shown in Fig. 2, the uptake of $\mathrm{Pb}^{2+}$ ions is $\mathrm{pH}$ dependent. At the low $\mathrm{pH}$ value of 3.0, RBL adsorbed lower amount $(56.4 \mathrm{mg} / \mathrm{g}$ or $57.8 \%$ ) of $\mathrm{Pb}^{2+}$ onto its surface active adsorption sites. With increase in solution $\mathrm{pH}$, the quantity adsorbed increased steadily until pH $5.0(70.6 \mathrm{mg} / \mathrm{g}$ or $71.6 \%)$ and $6.0(72.4 \mathrm{mg} / \mathrm{g}$ or $73.3 \%)$ where the quantities of $\mathrm{Pb}^{2+}$ adsorbed made a plateau on the graph before precipitation of $\mathrm{Pb}^{2+}$ ions set in. In summary, steady increment in adsorption was observed from $\mathrm{pH} 3.0$ to 5.0, indicating that more $\mathrm{Pb}^{2+}$ ions were adsorbed on RBL surfaces as $\mathrm{pH}$ increased. Then adsorption reached a plateau between $\mathrm{pH} 5.0$ and 6.0. The optimum $\mathrm{pH}$ for adsorption of $\mathrm{Pb}^{2+}$ was recorded at $\mathrm{pH}$ 5.0. Above this $\mathrm{pH}$, there was an apparent increase in adsorption of $\mathrm{Pb}^{2+}$. This has been attributed mainly to solvation and hydrolysis of $\mathrm{Pb}^{2+}$ ion products leading to precipitation of $\mathrm{Pb}^{2+}$ from solution. In aqueous solutions of $\mathrm{pH}$ less than $5, \mathrm{~Pb}^{2+}$ ions exist as either $\mathrm{Pb}^{2+}$ or $\mathrm{Pb}(\mathrm{OH})^{+}$ or both. However, the formation of $\mathrm{Pb}^{2+}$ hydrolysis products begins to occur at $\mathrm{pH}$ values between 5 and 6 , and this brings about precipitation. Due to this reason all the experiments were carried out at $\mathrm{pH} 5$.

\subsection{Adsorption kinetics}

The efficiency of RBL to remove $\mathrm{Pb}^{2+}$ metal from solution can be assessed by the rate of $\mathrm{Pb}^{2+}$ adsorption, and may be linked to its

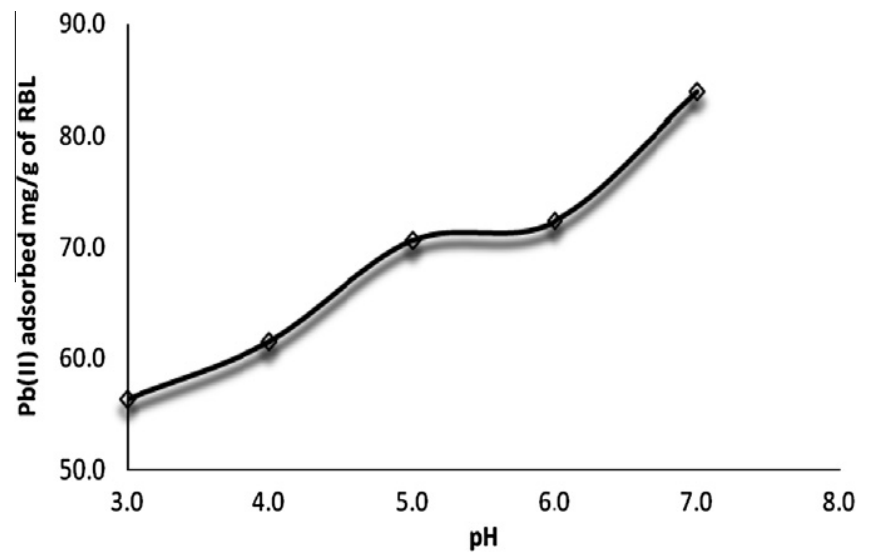

Fig. 2. Effect of $\mathrm{pH}$ on $\mathrm{Pb}^{2+}$ adsorption. 
efficiency to cleanup waste water. The effect of time $(5,15,30,60$, 180,360 , and $720 \mathrm{~min}$ ) on $\mathrm{Pb}^{2+}$ sorption was determined by equilibrating the RBL-sorbate aliquot at $\mathrm{pH} 5.0$ using $500 \mathrm{mg} / \mathrm{L} \mathrm{Pb}^{2+}$ solution. From the adsorption rate curve (Fig. 3), it was observed that $\mathrm{Pb}^{2+}$ adsorption was rapid and nearly completed in $30 \mathrm{~min}$ with $71.7 \%(70.8 \mathrm{mg} / \mathrm{g})$ of the total $\mathrm{Pb}^{2+}$ in solution adsorbed. As time elapsed, there was little or no adsorption until after $720 \mathrm{~min}$ when the percentage of $\mathrm{Pb}^{2+}$ adsorbed increased to $76.2 \%(75.3 \mathrm{mg} / \mathrm{g})$. This trend of adsorption may be explained thus: the initial rapid increase in $\mathrm{Pb}^{2+}$ uptake is due to the fact that a large number of vacant RBL surface sites are available for adsorption during the initial stage and since these have very high affinity for $\mathrm{Pb}^{2+}$, they are filled rapidly; after this initial rapid adsorption, the remaining vacant surface sites become very difficult to occupy due to the repulsive forces between the solute molecules on the solid and bulk phases. This result has shown that the breaking of these repulsive forces barrier and further adsorption are time dependent as seen after $720 \mathrm{~min}$. Hence, the time required to attain a rapid equilibrium is $30 \mathrm{~min}$. However, a contact time of 720 min has been employed for every other study because of this possibility of further adsorption.

Four kinetics models have been used to test the mechanism that controlled the sorption process: the pseudo-first order, pseudosecond order, Elovich and intra-particle diffusion models. Table 1 showing the comparative fits of the various models indicates that the kinetics data fit the pseudo-second-order kinetics better than for pseudo-first-order kinetics because the $r^{2}$ value as well as the experimental $q_{e}$ value of the pseudo-second-order is better correlated implying that $\mathrm{Pb}^{2+}$ adsorption is controlled by chemisorption involving sharing or exchange of electrons between sorbent and sorbate [29]. Intra-particle diffusion and Elovich models gave further insight into the kinetics models. Elovich curve, which did not pass through the origin (figure not shown), indicates there is some degree of boundary layer control. The linear intra-particle model also suggests that intra-particle diffusion is not the ratecontrolling step [30].

\subsection{Effect of adsorbent dose}

The effect of adsorbent dose on adsorption was evaluated by equilibrating the sorbent-sorbate mixture with $500 \mathrm{mg} / \mathrm{L}$ of $\mathrm{Pb}^{2+}$ at $\mathrm{pH} 5.0$ using varying masses in the range of $0.05-0.5 \mathrm{~g}$. It was observed (Fig. 4) that increasing the biomass dosage from a range $0.05 \mathrm{~g}$ through $0.50 \mathrm{~g}$ increased the percentage of $\mathrm{Pb}^{2+}$ removal from aqueous solution from $49.69 \%$ to over $99 \%$, while on the other hand, the equilibrium adsorption capacity, $q_{e}$, per mass of RBL was

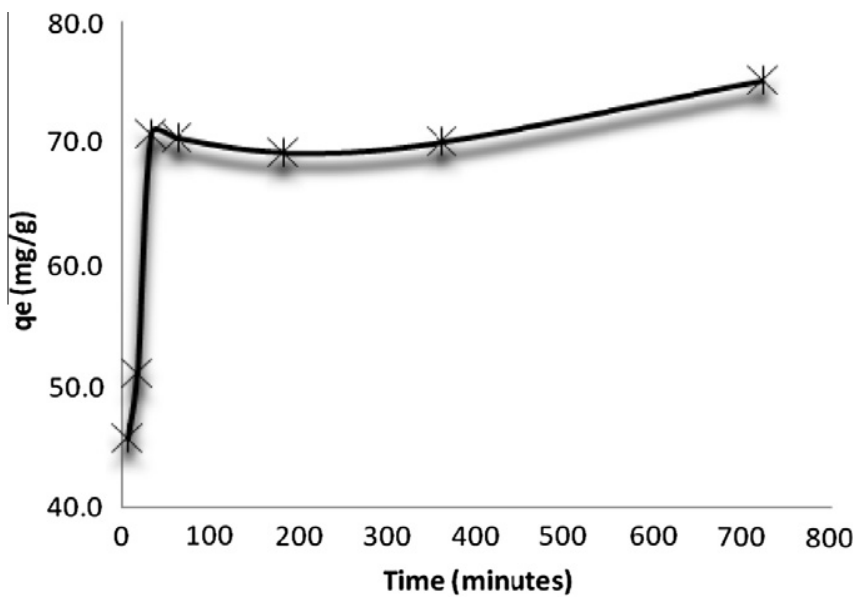

Fig. 3. Effect of time on $\mathrm{Pb}^{2+}$ adsorption.
Table 1

Sorption kinetics parameters.

\begin{tabular}{llll}
\hline Model & $\begin{array}{l}\text { Calculated } \\
\text { parameters }\end{array}$ & $\begin{array}{l}\text { Experimental } \\
\text { value }\end{array}$ & $r^{2}$ \\
\hline Pseudo-first-order & $\begin{array}{l}q_{e}=21.68 \mathrm{mg} / \mathrm{g} \\
K_{1}=0.009 \mathrm{~g} / \mathrm{mg} / \mathrm{min}\end{array}$ & $q_{e}=75.28 \mathrm{mg} / \mathrm{g}$ & 0.828 \\
Pseudo-second-order & $\begin{array}{l}q_{e}=76.92 \mathrm{mg} / \mathrm{g} \\
K_{2}=0.002 \mathrm{~g} / \mathrm{mg} / \mathrm{min}\end{array}$ & $q_{e}=75.28 \mathrm{mg} / \mathrm{g}$ & 0.998 \\
Elovich & $\begin{array}{l}q_{e}=57.34 \mathrm{mg} / \mathrm{g} \\
\beta=0.19\end{array}$ & $q_{t}=75.28 \mathrm{mg} / \mathrm{g}$ & 0.715 \\
& $\begin{array}{l} \\
\text { Intra-particle } \\
\text { diffusion }\end{array}$ & $R=80.36 \%$ & 0.702 \\
& $\alpha=0.091$ & & \\
\hline
\end{tabular}

found to decrease (98.26-19.94 mg/g) with increase biomass dose. Similar reports are found in literature [7,22]. It is apparent that by increasing the amount of RBL, available sorption sites for sorbentsolute interaction is increased due to increased available surface negative charges and decrease in the electrostatic potential near the RBL surface which favors sorbent-solute interaction; hence, leading to the noticed increased percentage $\mathrm{Pb}^{2+}$ removal from the aliquot solution. Unuabonah et al. [22] have attributed the $q_{e}$ decrease with increasing mass to the decreasing total surface area of the adsorbent and an increase in diffusion path length due to aggregation of RBL particles, and as the weight of the RBL increased, the aggregation becomes increasingly significant.

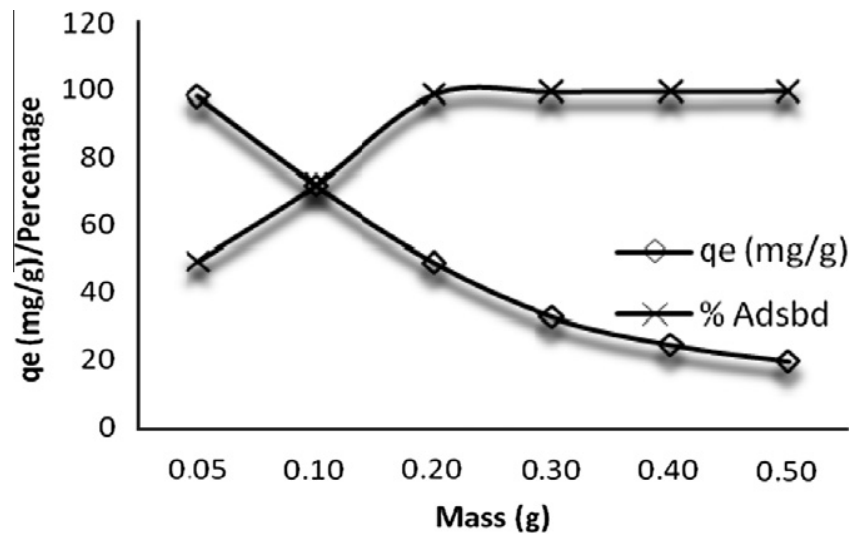

Fig. 4. Effect of varying biosorbent dose on $\mathrm{Pb}^{2+}$ adsorption.

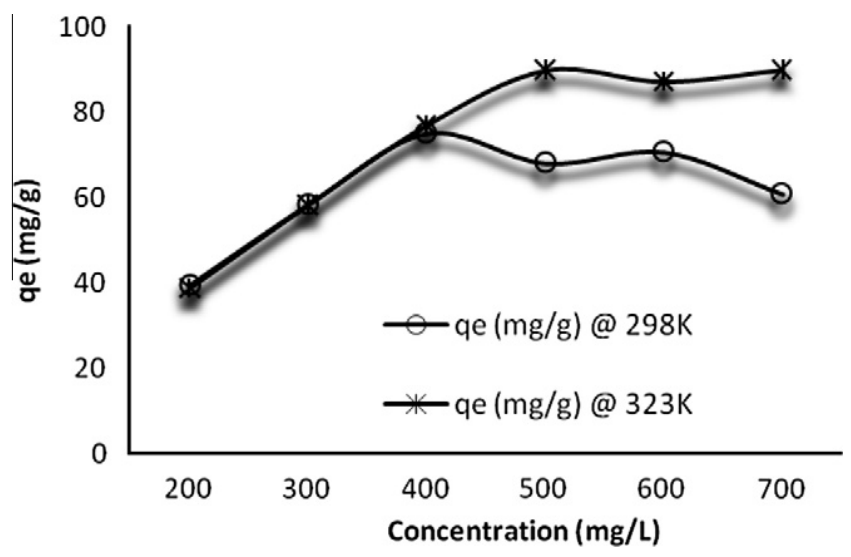

Fig. 5. Effect of initial adsorbate concentration on $\mathrm{Pb}^{2+}$ adsorption. 
Table 2

Adsorption isotherms parameters.

\begin{tabular}{|c|c|c|c|c|c|c|}
\hline \multirow[t]{2}{*}{ Isotherm } & \multicolumn{2}{|c|}{ Calculated parameter } & \multicolumn{2}{|l|}{ Experiment value } & \multicolumn{2}{|l|}{$r^{2}$} \\
\hline & $25^{\circ} \mathrm{C}$ & $50^{\circ} \mathrm{C}$ & $25^{\circ} \mathrm{C}$ & $50^{\circ} \mathrm{C}$ & $25^{\circ} \mathrm{C}$ & $50{ }^{\circ} \mathrm{C}$ \\
\hline Langmuir & $\begin{array}{l}Q_{0}=62.50 \mathrm{mg} / \mathrm{g} \\
b=0.19\end{array}$ & $\begin{array}{l}90.91 \mathrm{mg} / \mathrm{g} \\
0.00\end{array}$ & $q_{e}=70.21 \mathrm{mg} / \mathrm{g}$ & $89.81 \mathrm{mg} / \mathrm{g}$ & 0.993 & 0.999 \\
\hline Freundlich & $\begin{array}{l}n=16.13 \\
K_{f}=49.66\end{array}$ & $\begin{array}{l}7.58 \\
47.86\end{array}$ & & & 0.588 & 0.719 \\
\hline D-R. & $X_{m}=53.46 \mathrm{mg} / \mathrm{g}$ & $55.48 \mathrm{mg} / \mathrm{g}$ & $q_{t}=70.21 \mathrm{mg} / \mathrm{g}$ & $89.81 \mathrm{mg} / \mathrm{g}$ & 0.237 & 0.554 \\
\hline
\end{tabular}

D-R. = Dubinin-Radushkevich.

\subsection{Adsorption isotherms and thermodynamics}

The effects of sorbate concentrations and temperature on adsorption were done using varying $\mathrm{Pb}^{2+}$ concentrations between 200 and $700 \mathrm{mg} / \mathrm{L}$ at $25 \pm 2{ }^{\circ} \mathrm{C}$ and $50 \pm 2{ }^{\circ} \mathrm{C}$. Results (Fig. 5) show that increase in reaction temperature from 298 to $323 \mathrm{~K}$, did not seem to affect amount of $\mathrm{Pb}^{2+}$ adsorption onto the surface of $\mathrm{RBL}$ at lower concentrations until maximum sorption which occurred at $400 \mathrm{mg} / \mathrm{L}$ of $\mathrm{Pb}^{2+}$ concentration in solution. Then increase in temperature led to an increase in the amount of $\mathrm{Pb}^{2+}$ metal adsorbed (from $\approx 77 \mathrm{mg} / \mathrm{g}$ to $\approx 90 \mathrm{mg} / \mathrm{g}$ ) as concentration of the metal increased from $400 \mathrm{mg} / \mathrm{L}$ to $500 \mathrm{mg} / \mathrm{L}$, while there was no noticeable change in amount of $\mathrm{Pb}^{2+}$ metal adsorbed at $298 \mathrm{~K}$. Thus, temperature enhanced the reactions between of $\mathrm{Pb}^{2+}$ ions and the RBL surface functional groups. However, further increase in $\mathrm{Pb}^{2+}$ concentration at the higher temperature did not cause any increase in adsorption. Thus, to increase rate and efficiency of adsorption of $\mathrm{Pb}^{2+}$ on $\mathrm{RBL}$ as well as reduce the effect of the repulsive forces discussed in Section 3.3, high reaction temperature is recommended.

Langmuir, Freundlich and Dubinin-Radushkevich sorption isotherms (Table 2) were used to assess the RBL adsorption capacity and surface sorption properties. Langmuir isotherm, which is based on the assumption that all sites possess equal affinity for the sorbate while forming a sorbate monolayer on the biosorbent surface at saturation, gave better fit to the sorption data than the Freundlich model which assumes sorption on heterogeneous surfaces [4]. The Dubinin-Radushkevich sorption isotherm which combines both assumptions did not fit the sorption data. The estimated monolayer adsorption capacity $\left(Q_{0}\right)$ is 62.50 and $90.91 \mathrm{mg} / \mathrm{g}$ at $298 \mathrm{~K}$ and $323 \mathrm{~K}$ respectively.

Table 3 shows the thermodynamic parameters obtained. The free energy changes $\left(\Delta G^{o}\right)$ were positive with values of $76.8 \mathrm{~kJ} /$ $\mathrm{mol}$ and $83.3 \mathrm{~kJ} / \mathrm{mol}$ at $298 \mathrm{~K}$ and $323 \mathrm{~K}$ respectively. The calculated values of enthalpy $\Delta H^{\circ}$ were positive and imply that the reaction is an exothermic process and releases energy. As the diffusion process was exothermic in nature, it is expected that increased solution temperature would result in decreased uptake of $\mathrm{Pb}^{2+}$ ions from aqueous solution. However, energy is needed to break the repulsive forces hindering further $\mathrm{Pb}^{2+}$ adsorption and thus higher temperature led to higher adsorption. The entropy $\Delta S^{o}$ of the reaction was negative due to the fact that the displaced molecules from RBL surfaces lost more translational entropy than was gained by the $\mathrm{Pb}^{2+}$ ions, thus, there will be decreased randomness at the $\mathrm{RBL} /$ solution interface.

Table 3

Thermodynamic parameters for $\mathrm{Pb}^{2+}$ adsorption process.

\begin{tabular}{lcc}
\hline & $T=298 \mathrm{~K}$ & $T=323 \mathrm{~K}$ \\
\hline$\Delta G^{o}(\mathrm{KJ} / \mathrm{mol})$ & 76.8 & 83.3 \\
$\Delta H^{o}(\mathrm{KJ} / \mathrm{mol})$ & -30315.6 & -32858.8 \\
$\Delta S^{o}(\mathrm{KJ} / \mathrm{mol})$ & -0.258 & -0.258 \\
\hline
\end{tabular}

Table 4

Review of maximum sorption capacity $\left(Q_{\max }\right)$ for $\mathrm{Pb}^{2+}$ sorption by different biosorbents reported in the literature.

\begin{tabular}{lll}
\hline Biomass & $\mathrm{Pb}^{2+} Q_{\max }(\mathrm{mg} / \mathrm{g})$ & Ref. \\
\hline Modified orange peel & 476.1 & {$[29]$} \\
Ulva sp. & 302.5 & {$[31]$} \\
Padina sp. & 259.0 & {$[31]$} \\
Sargassum sp. & 240.4 & {$[31]$} \\
Waste maize bran & 142.86 & {$[32]$} \\
Orange peel & 113.5 & {$[29]$} \\
Lignin & 102.40 & {$[8]$} \\
Gracilliiaria sp. & 93.2 & {$[31]$} \\
RBL & 89.8 at $323 \mathrm{~K}$ & Present study \\
Tea leaves & 78.87 & {$[9]$} \\
RBL & 70.21 at $298 \mathrm{~K}$ & Present study \\
Sago & 46.60 & {$[33]$} \\
Tree fern & 40.00 & {$[10]$} \\
Groundnut husks & 39.40 & {$[11]$} \\
Sphagnum moss peat & 30.70 & {$[12]$} \\
Hazelnut shell & 28.18 & {$[6]$} \\
Sawdust & 21.05 & {$[13]$} \\
Rice hulls & 11.40 & {$[34]$} \\
Chitosan & 8.31 & {$[14]$} \\
Almond shell & 8.08 & {$[6]$} \\
\hline
\end{tabular}

The $\mathrm{Pb}^{2+}$ adsorption capacities of some alternative biosorbents reported in literature have been tabulated in Table 4 and compared with that of RBL. It shows that RBL adsorption capacity is much higher than most biosorbents reported in literature. Thus, its good adsorption capacity, ease of sample treatment, as well as availability makes $\mathrm{RBL}$ a promising cost-effective biosorbent for $\mathrm{Pb}^{2+}$ removal from aqueous environment.

\section{Conclusion}

The ability of $B$. lambarenensis biosorbent to remove $\mathrm{Pb}^{2+}$ from aqueous solution was investigated in equilibrium, kinetics and thermodynamics studies. The results obtained show that the biomass of $B$. lambarenensis has an optimum $\mathrm{pH}$ for $\mathrm{Pb}^{2+}$ adsorption at 5.0, nearly attains maximum adsorption within $1 \mathrm{~h}$ at $298 \mathrm{~K}$, and obeys the pseudo-second order kinetics with an exothermic reaction. $\mathrm{Pb}^{2+}$ adsorption increased with increase in temperature. The Langmuir isotherm described the equilibrium data better than other isotherms indicating adsorption is monolayer with monolayer adsorption capacity of $62.50 \mathrm{mg} / \mathrm{g}$ at $298 \mathrm{~K}$ and $90.91 \mathrm{mg} / \mathrm{g}$ at $323 \mathrm{~K}$. The FT-IR analysis showed that possible functional groups responsible for metal adsorption are carboxyl, carbonyl, amides, hydroxyl and possibly other smaller groups that cannot be identified using only FT-IR spectra. Taking into account its good adsorption capacity, ease of sample treatment, as well as availability, the biomass of $B$. lambarenensis is a promising cost-effective biosorbent for $\mathrm{Pb}^{2+}$ removal from aqueous environment. 


\section{References}

[1] E.I. Unuabonah, B.I. Olu-Owolabi, K.O. Adebowale, A.E. Ofomaja, Adsorption of lead and cadmium ions from aqueous solutions by tripolyphosphateimpregnated Kaolinite clay, Colloids Surf. A: Physicochem. Eng. Asp. 292 (2007) 202-211.

[2] M.N.M. Ibrahim, W.S.W. Ngah, M.S. Norliyana, W.R.W. Daud, M. Rafatullah, O. Sulaiman, et al., A novel agricultural waste adsorbent for the removal of lead (II) ions from aqueous solutions, J. Hazard. Mater. 182 (2010) 377-385.

[3] T.A. Kurniawan, G.Y.S. Chan, W. Lo, S. Babel, Comparisons of low-cost adsorbents for treating wastewaters laden with heavy metals, Sci. Total Environ. 366 (2006) 409-426.

[4] C. Yan, G. Li, P. Xue, Q. Wei, Q. Li, Competitive effect of Cu(II) and Zn(II) on the biosorption of lead(II) by Myriophyllum spicatum, J. Hazard. Mater. 179 (2010) 721-728.

[5] A. Saeed, M. Iqbal, W.H. Holl, Kinetics, equilibrium and mechanism of $\mathrm{Cd}^{2+}$ removal from aqueous solution by mungbean husk, J. Hazard. Mater. 168 (2009) 1467-1475.

[6] E. Pehlivan, T. Altun, S. Cetin, M.I. Bhanger, Lead sorption by waste biomass of hazelnut and almond shell, J. Hazard. Mater. 167 (2009) 1203-1208.

[7] A.E. Ofomaja, E.B. Naidoo, S.J. Modise, Removal of copper(II) from aqueous solution by pine and base modified pine cone powder as biosorbent, J. Hazard. Mater. 168 (2009) 909-917.

[8] X. Guo, S. Zhang, X. Shan, Adsorption of metal ions on lignin, J. Hazard. Mater. 151 (2008) 134-142.

[9] W.T. Tan, M.K. Abd Rahman, Removal of lead, cadmium and zinc by waste tea leaves, Environ. Technol. Lett. 9 (1998) 1223-1232.

[10] Y.S. Ho, W.T. Chiu, C.S. Hsu, C.T. Huang, Sorption of lead ions from aqueous solution using tree fern as a sorbent, Hydrometallurgy 73 (2004) 55-61.

[11] F.E. Okieimen, E.U. Okundia, D.E. Ogbeifun, Sorption of cadmium and lead ions on modified groundnut (Arachis hypogea) husks, J. Chem. Technol. Biotechnol. 51 (1991) 97-103.

[12] Y.S. Ho, D.A.J. Wase, C.F. Forster, Kinetic studies of competitive heavy metal adsorption by sphagnum moss peat, Environ. Technol. 17 (1996) 71-77.

[13] Q. Li, J. Zhai, W. Zhang, M. Wang, J. Zhou, Kinetic studies of adsorption of $\mathrm{Pb}(\mathrm{II})$, $\mathrm{Cr}(\mathrm{III})$ and $\mathrm{Cu}(\mathrm{II})$ from aqueous solution by sawdust and modified peanut husk, J. Hazard. Mater. 141 (2007) 163-167.

[14] M.M.D. Zulkali, A.L. Ahmad, N.H. Norulakmal, N.S. Sharifah, Comparative studies of Oryza sativa L. husk and chitosan as lead adsorbent, J. Chem. Technol. Biotechnol. 81 (2006).

[15] K.A. Krishnan, T.S. Anirudhan, Removal of cadmium(II) from aqueous solutions by steam-activated sulphurised carbon prepared from sugar-cane bagasse pith: kinetics and equilibrium studies, Water SA 29 (2003) 147-156.

[16] N. Meunier, J. Laroulandie, J.F. Blais, R.D. Tyagi, Cocoa shells for heavy metal removal from acidic solutions, Biores. Technol. 90 (2003) 255-263.

[17] M. Ajmal, R.A.K. Rao, S. Anwar, J. Ahmad, R. Ahmad, Adsorption studies on rice husk: removal and recovery of Cd(II) from wastewater, Biores. Technol. 86 (2003) 147-149.
[18] A.O. Ogunfowokan, O.I. Asubiojo, A.A. Adeniyi, E.A. Oluyemi, Trace Pb, Zn, and $\mathrm{Cu}$ in Barbula Lambarenensis as a monitor of local atmospheric pollution in IleIfe, Nigeria, J. Appl. Sci. 4 (2004) 380-383.

[19] G.W. Sears, Determination of specific surface area of colloidal silica by titration with sodium hydroxide, Anal. Chem. 28 (1956) 1981-1983.

[20] R.K. Iler, The Chemistry of Silica, John Wiley \& Sons, New York, 1979. pp. 203206, 243.

[21] M. Radojevic, V.N. Bashkin, Practical Environmental Analysis, Royal Society of Chemistry, Cambridge, 1998.

[22] E.I. Unuabonah, K.O. Adebowale, B.I. Olu-Owolabi, L.Z. Yang, L.X. Kong, Adsorption of $\mathrm{Pb}$ (II) and $\mathrm{Cd}$ (II) from aqueous solutions onto sodium tetraborate-modified Kaolinite clay: equilibrium and thermodynamic studies, Hydrometallurgy 93 (2008) 1-9.

[23] G. Sposito, The Chemistry of Soils, Oxford University Press, New York, NY, 1989.

[24] M. Mohammad, S. Maitra, N. Ahmad, A. Bustam, T.K. Sen, B.K. Dutta, Metal ion removal from aqueous solution using physic seed hull, J. Hazard. Mater. 179 (2010) 363-372.

[25] S. Lagergren, About the theory of so-called adsorption of soluble substances, Kungliga Svenska Vetenskapsakademiens Handlingar 24 (1898) 1-39.

[26] E. Demirbas, M. Kobya, E. Senturk, T. Ozkan, Adsorption kinetics for the removal of chromium (VI) from aqueous solutions on the activated carbons prepared from agricultural wastes, Water SA 30 (2004) 533-5400.

[27] S. Chakravarty, A. Mohanty, T.N. Sudha, A.K. Upadhyay, J. Konar, J.K. Sircar, et al., Removal of $\mathrm{Pb}(\mathrm{II})$ ions from aqueous solution by adsorption using bael leaves (Aegle marmelos), J. Hazard. Mater. 173 (2010) 502-509.

[28] Z.-Y. Yao, J.-H. Qi, L.-H. Wang, Equilibrium, kinetic and thermodynamic studies on the biosorption of $\mathrm{Cu}(\mathrm{II})$ onto chestnut shell, J. Hazard. Mater. 174 (2010) $137-143$.

[29] N. Feng, X. Guo, S. Liang, Y. Zhu, J. Liu, Biosorption of heavy metals from aqueous solutions by chemically modified orange peel, J. Hazard. Mater. 185 (2011) 49-54.

[30] M.A. Tofighy, T. Mohammadi, Adsorption of divalent heavy metal ions from water using carbon nanotube sheets, J. Hazard. Mater. 185 (2011) 140-147.

[31] P.X. Sheng, Y. Ting, J.P. Chen, L. Hong, Sorption of lead, copper, cadmium, zinc, and nickel by marine algal biomass: characterization of biosorptive capacity and investigation of mechanisms, J. Colloid Interface Sci. 275 (2004) 131-141.

[32] K.K. Singh, A.K. Singh, S.H. Hasan, Low cost biosorbent 'wheat bran' for the removal of cadmium from wastewater: kinetic and equilibrium studies, Bioresour. Technol. 97 (2006) 994-1001.

[33] S.Y. Quek, D.A.J. Wase, C.F. Forster, The use of sago waste for the sorption of lead and copper, Water SA 24 (1998) 251-256.

[34] M.N.V. Prasad, H. FreItas, Removal of toxic metals from solution by leaf, stem and root phytomass of Quercus ilex L. (holly oak), Environ. Pollut. 110 (2000) $277-283$. 